\title{
El cooperativismo agrario en regiones marginales. Aciertos y fracasos en el Nordeste Argentino (NEA), 1920-1960
}

\author{
Agrarian Cooperatives in marginal regions. Successes and Failures \\ in the Argentine North East, 1920-1960
}

\author{
NOEMÍ M. GIRBAL-BLACHA \\ CONICET-UNQ, Argentina
}

\begin{abstract}
RESUMEN
La región del Nordeste argentino representa un $17 \%$ del territorio de casi 3 millones de $\mathrm{km}^{2}$ del país; sostiene su economía en la explotación forestal y en dos productos típicos: el algodón y el tabaco, a través de los cuales esta economía regional se vincula al modelo agroexportador argentino a partir de fines del siglo XIX. Desde los tiempos de la primera posguerra, tabaco y algodón cobran relieve en el mercado interno, expandido junto con la industrialización sustitutiva de importaciones. La industria textil y la manufactura de cigarrillos se expanden. En

el caso del algodón el cooperativismo juega

para el productor un papel significativo promoviendo el asociacionismo, mientras vende la materia prima y lo provee de insumos. Diferente es el caso del tabaco. Aquí el cooperativismo no prospera, con productores ocupantes precarios de la tierra. El grado de concentración industrial, el origen de la mano de obra, el tipo de procesamiento de la materia prima y la interlocución con el Estado, para uno y otro caso, son analizados para conocer los aciertos y fracasos del cooperativismo agrario,

entre 1920 y 1960, en economías marginales donde la reinversión de las ganancias es escasa.
\end{abstract}

PALABRAS CLAVE: Cooperativismo, Agricultura, Región, Marginalidad

Códigos JEL: D2, N5, R5, O2

\section{ABSTRACT}

The North-Eastern region of Argentina covers $17 \%$ of the almost 3-million-square-kilometer territory of the country. Its economy is sustained by forest exploitation and by two distinctive agricultural products: cotton and tobacco. It is through these two products that the regional economy plays a role in the agricultural export model of Argentina, which was established in the last two decades of the $19^{\text {th }}$ century and which continued well into the $20^{\text {th }}$ century. From the first post-war period, both tobacco and cotton gained importance as they were produced for a domestic market that had grown with the import substitution industrialization. The textile industry and the manufacture of cigarettes found the roots for their expansion in these two products. In the case of cotton, the cooperative movement played a significant role for the producer promoting associationism while selling raw material and acquiring supplies. Cooperatives often channeled their interests. For tobacco the cooperative movement did not flourish in the same way, in spite of being an agricultural product from the same region and in spite of the fact that the producers were precarious landholders. In both cases, it is worth analyzing the degree of industrial density, the origin of the work force, the kind of process the raw materials went through, and the dialogue with the State, in order to recognize the successes and failures of agrarian cooperatives between 1920 and 1960 in marginal economies where the reinvestment of profits is scarce.

KEY WORDS: Cooperatives Movement, Agriculture, Region, Marginality

JEL Codes: D2, N5, R5, O2 


\section{REPÚBLICA ARGENTINA.}

División Política

Provincias que integran las regiones del NEA y el NOA
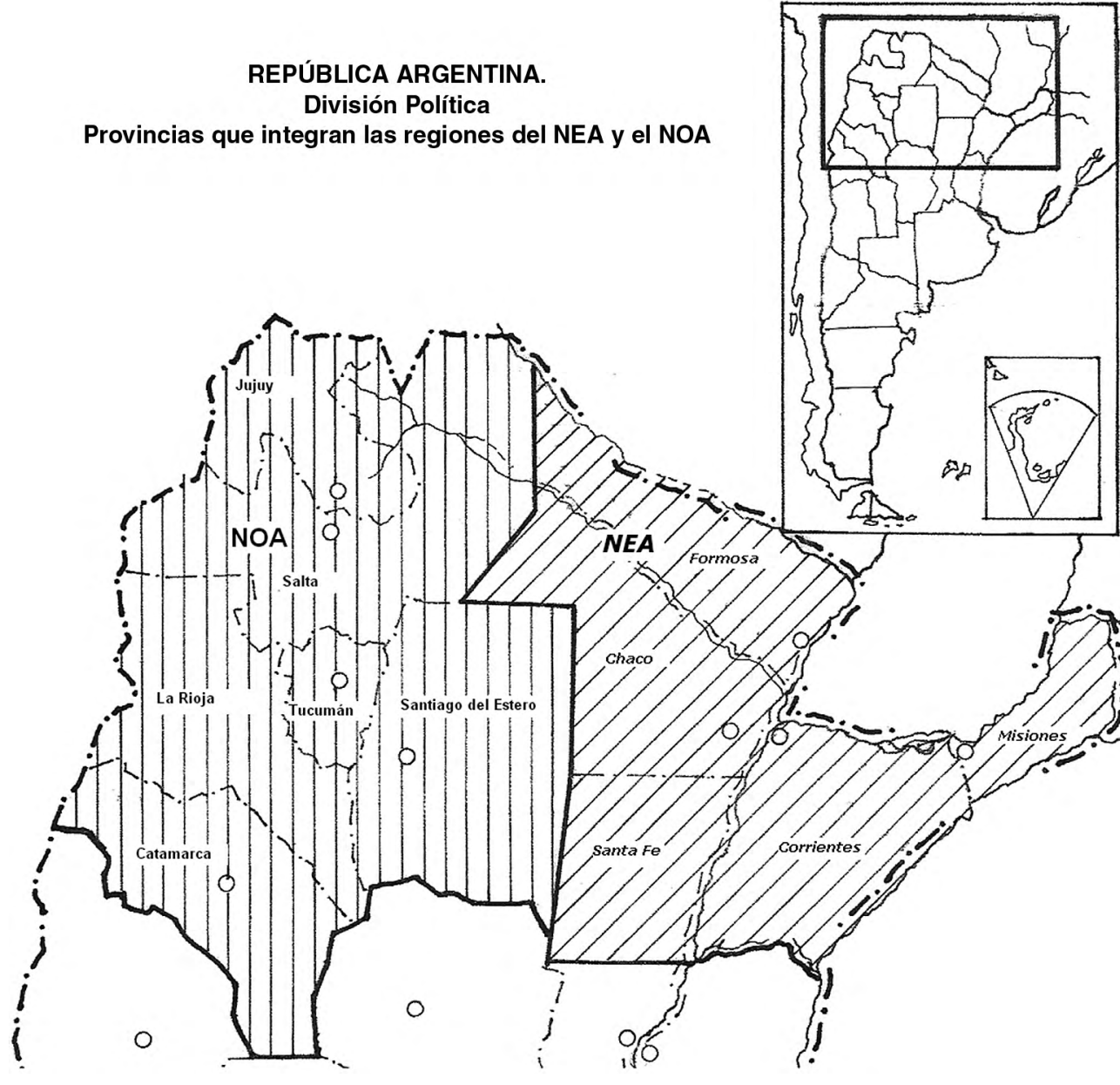

O
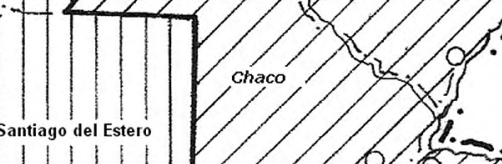

0
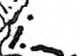


\section{Introducción ${ }^{1}$}

$\mathrm{L}$

as pautas corporativas de los sectores rurales en la Argentina fueron, por lo general, respuestas a procesos de crisis de distinto tipo. En 1866 como resultado directo de la crisis ganadera ocurrida en la región pampeana, se conforma la Sociedad Rural Argentina que agrupa a los grandes terratenientes y estancieros locales. En 1887 -luego de la crisis financiera de 1873 a 1875 que impulsara la creación del Club Industrial - se conforma la Unión Industrial Argentina en momentos en que la industria es sinónimo de agroindustrias. En 1894 frente a la crisis de superproducción azucarera los agroindustriales de este ramo integran el Centro Azucarero Nacional; ocho años más tarde hacen lo propio los vitivinicultores cuando se organizan en el Centro Vitivinícola Nacional y, en 1912, la revuelta de los arrendatarios y aparceros santafesinos (Alcorta) gesta una entidad gremial como la Federación Agraria Argentina. Son éstos los inicios de la acción corporativa de productores y agroindustriales que se expresan como una respuesta colectiva - aunque no mediante cooperativas- para presionar al Estado frente a la necesidad de encontrar soluciones que atemperen sus crisis sectoriales. Todas estas entidades aún perduran mientras el cooperativismo - especialmente en la rica región pampeana- ha entrado en la Argentina en franca declinación al amparo del neoliberalismo de los años de 1990, para dar paso a organizaciones que mucho se asemejan a sociedades anónimas.

Con otros perfiles de afiliación también surgen tempranamente en la Argentina, las cooperativas agrarias. Entre 1919 y 1921 los congresos cooperativos logran significativas resoluciones. Es un período en el cual la agricultura y sus productores reciben los benéficos efectos de la reforma de la Carta Orgánica del Banco Hipotecario Nacional (1919) y de la primera ley nacional de arrendamientos rurales (1921). Esas disposiciones y la acción de las cooperativas agrarias organizadas entre 1918 y 1926, junto con la ley cooperativa de la provincia de Buenos Aires de 1922, preparan el ambiente propicio para dictar una legislación cooperativista de alcance nacional el 20 de diciembre de 1926. Es entonces cuando se sanciona y promulga la ley de cooperativas 11.388 que otorga estatuto legal —en el marco de la política nacional- a estas instituciones; parte activa en la comercialización de productos primarios, su acción promueve la baja de los costos de intermediación, mientras agrupa y da auxilio a los productores rurales ${ }^{2}$.

Buenos Aires, Santa Fe, Córdoba, Entre Ríos, La Pampa, son muestrarios de la consolidación del movimiento cooperativo agrario, que se extiende en los años 30 hacia el Territorio Nacional del Chaco y su explotación algodonera, cuyo origen temprano puede encontrarse en 1919 cuando se funda allí la Cooperativa Agrícola Algodonera Ltda. de Margarita Belén. La función productora e industrializadora de las cooperativas se consolida fuera de las áreas marginales del territorio argentino, mientras en el NEA ven decrecer su representación sobre el total, de un $12 \%$ en 1937 a un $5 \%$ en 1951 (Cuadro 1). Su expresión más exitosa se asocia a la ganadería, a la producción lechera y de granos de la pampa.

La región NEA (Nordeste Argentino) representa un 17\% del territorio de casi 3 millones de $\mathrm{km}^{2}$ con que cuenta la República Argentina; sostiene su economía en la explotación forestal y en dos productos agrícolas típicos: el algodón y el tabaco. Es a través de ellos que esta economía regional se vincula al modelo agroexportador argentino, estructurado en las últimas

[Fecha de recepción del original, 2 de febrero de 2009. Versión definitiva, 10 de agosto de 2009].

1 Versión preliminar presentada en el IX Congreso de la Asociación Española de Historia Económica, Murcia (España), setiembre de 2008.

2 Thiery (1955), pp. 181-190, Girbal-Blacha (1988). 
CUADRO 1

COOPERATIVAS AGROPECUARIAS EN LA ARGENTINA. 1937-1947-1951

\begin{tabular}{|c|c|c|c|c|c|c|c|c|c|}
\hline \multirow[b]{2}{*}{$\begin{array}{l}\text { Clase de } \\
\text { Cooperativa }\end{array}$} & \multicolumn{3}{|c|}{1937} & \multicolumn{3}{|c|}{1947} & \multicolumn{3}{|c|}{1951} \\
\hline & $\mathrm{N} .^{\circ}$ & $\begin{array}{l}\mathrm{N} .^{\circ} \\
\text { socios }\end{array}$ & $\begin{array}{l}\text { Capital } \\
\text { realizado } \\
m \$ n\end{array}$ & N. ${ }^{\circ}$ & $\begin{array}{c}\mathrm{N} .^{\circ} \\
\text { socios }\end{array}$ & $\begin{array}{l}\text { Capital } \\
\text { realizado } \\
m \$ n\end{array}$ & N. ${ }^{\circ}$ & $\begin{array}{c}\mathrm{N} .{ }^{\circ} \\
\text { socios }\end{array}$ & $\begin{array}{l}\text { Capital } \\
\text { realizado } \\
m \$ n\end{array}$ \\
\hline Agroganaderas & 138 & 33.233 & 6.551 .930 & 192 & 61.729 & $13.045 .093,76$ & 434 & 124.095 & $40.565 .169,41$ \\
\hline Algodoneras & 20 & 2.970 & 1.191 .230 & 29 & 9.132 & $6.687 .451,45$ & 31 & 11.522 & $13.993 .600,54$ \\
\hline Granjeras & - & - & - & 7 & 945 & $89.063,10$ & 15 & 2.468 & $370.015,50$ \\
\hline Tamberas & 78 & 3.217 & 1.513 .260 & 357 & 22.941 & $14.731 .156,22$ & - & - & - \\
\hline Vinifrutícolas & 29 & 1.182 & 1.541 .820 & 26 & 2.946 & $2.833 .465,68$ & 46 & 5.399 & $7.944 .169,05$ \\
\hline Yerbateras & 13 & 1.590 & 383.300 & 17 & 8.012 & $1.813 .687,16$ & 18 & 8.725 & $3.786 .014,08$ \\
\hline Tabacaleras Molineras & - & - & - & - & - & - & 400 & 28.861 & $23.668 .795,65$ \\
\hline TOTAL & 278 & 42.182 & 11.181 .540 & 628 & 105.705 & $39.199 .917,37$ & 944 & 181.070 & $90.330 .764,23$ \\
\hline
\end{tabular}

Fuente: YURI IZQUIERDO (1972), p. 62.

dos décadas del siglo XIX y que perdura hasta avanzado el siglo $\mathrm{xX}$, como en gran parte de América Latina. Desde los tiempos de la primera posguerra, tabaco y algodón cobran relieve, en tanto producen para un mercado interno expandido junto con la industrialización sustitutiva de importaciones. La industria textil y la manufactura de cigarrillos encuentran en estas materias primas la base de su expansión.

En el caso del algodón el cooperativismo juega, para el productor, un papel significativo a la hora de promover el asociacionismo, vender la materia prima y proveerse de insumos. Las cooperativas canalizan con frecuencia sus intereses. Para el tabaco, cuyo cultivo depende del productor estacionario y, en consecuencia es escaso el esfuerzo para mejorar el tipo producido mientras la industrialización tabacalera aparece altamente concentrada, el cooperativismo no prospera del mismo modo. Se trata de un producto agrícola típico de la misma región y con productores precarios de la tierra, pero en ambos casos no es igual la acción del asociacionismo ${ }^{3}$.

El grado de concentración industrial, el origen de la mano de obra, el tipo de procesamiento de la materia prima y la interlocución con el Estado, para uno y otro caso, merecen ser analizados para conocer los aciertos y los fracasos del cooperativismo agrario, entre 1920 y 1960, en economías marginales donde la reinversión de las ganancias es escasa y apenas iniciada la segunda mitad del siglo xx cambia la demanda, disminuye el consumo y aparecen productos competitivos. Es éste el objetivo de este trabajo, que coloca la presencia y la acción del movimiento cooperativo en el centro del escenario rural nordestino.

\section{La economía agraria del NEA y el reinado del "oro blanco"}

Aunque desde los inicios del siglo xx el Ministerio de Agricultura de la Nación comienza a fomentar la siembra de semillas seleccionadas de algodón en el $\mathrm{NEA}^{4}$, recién hacia 1920

Girbal-Blacha (2005), pp. 91-120 y (2007), pp. 83-105.

En 1905 el Chaco cuenta con su primera cooperativa algodonera en la colonia Margarita Belén. 
— cuando la explotación forestal de esa región inicia su declinación y desde 1921 se aprueba la creación de nuevas colonias agro-pastoriles en el territorio chaqueño- el cultivo del algodón adquiere real importancia. Se dejan sentir los efectos de la posguerra y los precios internacionales del producto suben desde 1923 debido a la plaga que ataca el algodón en los Estados Unidos. El Ministro de Agricultura Tomás Le Bretón, aprovecha la coyuntura y logra atraer el interés de la Sociedad Rural Argentina — que otorga premios a la calidad del algodón-y hasta los comentarios de la Review of the River Plate ${ }^{5}$. La economía del Gran Chaco Argentino (NEA) se identifica en el largo plazo prácticamente con este cultivo.

En 1924-25 las facilidades que el gobierno concede para colonizar el Chaco, incrementa la superficie algodonera, superando las 110.000 hectáreas. El Ministerio de Agricultura nacional persiste en mejorar la calidad del producto y contrata — una vez más - a reconocidos técnicos y expertos norteamericanos ${ }^{6}$. Es un período en que las ganancias por hectárea de cultivo se estiman en \$ 68 para el maíz, \$ 170 para la caña de azúcar y \$ 299 para el algodón 7 . Los agrónomos regionales subrayan que la riqueza de Corrientes, el Chaco y Formosa "depende de esos capullos blancos como la nieve inmaculada de los Andes" y hasta el Ferrocarril Nordeste Argentino decide recabar la opinión de la British Cotton Association para valorar la calidad del producto de origen nacional ${ }^{8}$. Mientras tanto, sobre la base de las recomendaciones de los técnicos estadounidenses contratados se destaca la importancia de la maquinaria para desmotar el algodón. Abundan los consejos prácticos para el cultivador y se alienta el desarrollo del cooperativismo algodonero'.

El cultivo del algodón y la industria de hilados y tejidos nacionales guardan una relación estrecha desde la década de 1920. En mayo de 1924 el Presidente de "Manufactura Algodonera Argentina" — constituida con fábricas en Rosario, Buenos Aires y Resistencia y con una inversión superior a los $\mathrm{m} \$ \mathrm{n} 5$ millones- espera acrecentar los negocios y reclama para conseguirlo la protección a través de aforos que protejan a la industria textil de la competencia externa. Auxilio similar pide la "Compañía General de Fósforos S.A." con fábrica instalada en Resistencia (Chaco) "para independizar a la empresa de la importación de todos aquellos productos susceptibles de ser elaborados y producidos en el país, para lo cual se entregó de lleno a la producción de algodón", tanto para el desmote de la fibra como para preparar el aceite de la semilla. La empresa complementa estas actividades con las de su planta de Bernal (provincia de Buenos Aires) donde hila el algodón y fabrica el pabilo destinado a los fósfo$\operatorname{ros}^{10}$. El cultivo algodonero y su industrialización se vuelven importantes para otras empresas radicadas en el Norte. El Ingenio Las Palmas (en el Chaco) y la Compañía Azucarera Tucumana (en Tucumán), entre otros, son expresiones de diversificación inversora para aumentar las ganancias, minimizando los riesgos ${ }^{11}$.

Kaplan de Drimer y Kaplan (1975), p. 519.

Guy (2000).

Muello (s/f), p. 63.

La Gaceta Algodonera (GA en adelante), Buenos Aires, febrero 29 de 1924, año 1, núm. 1, pp. 1-15; noviembre 30 de 1924, año 1, núm. 10, pp. 1-2.

$9 \quad$ Más datos en Guy (2000).

10 GA, Buenos Aires, mayo 31 de 1924, año 1, núm. 4, pp. 1-4, 12 y 15-16; febrero 28 de 1927, año 2, núm. 37, pp. 25-30, 40-42.

11 Guy (2000). Las dificultades por las que pasa la economía algodonera argentina, no resultan preocupantes sólo para quienes viven de ella, sino también para los técnicos estadounidenses que prestaran su asesoramiento para radicar el cultivo del algodón en el Chaco. Nathaniel Winters y Ernest L. Tutt así lo expresan —en más de una oportunidad — ante los miembros de la Cámara de Comercio Norteamericana. 
La atracción de mano de obra, "de correntinos y santiagueños", no se hace esperar ${ }^{12}$. Desde 1924 el Ministerio de Agricultura promueve el ingreso de inmigrantes alemanes ante la "falta de brazos para la recolección del algodón" en el Chaco. Es lo que ocurre en 1925 y por esta razón la Sociedad Rural local se dirige al Ministerio pidiéndole la colaboración para atraer braceros a la cosecha del algodón. Los avisos en La Gaceta Algodonera registran este pedido. De todos modos, se sigue alentando la pequeña industria del hilado y del tejido doméstico, considerándose que "la manualidad en el hogar es altamente moral"13. Un decenio después unos 276.000 pobladores chaqueños proceden de provincias vecinas; sumándose a ellos la llegada del extranjero promovida por el Estado Nacional; una corriente que entre 1923 y 1936 radica en la planicie centro-chaqueña unos 20.000 inmigrantes.

Como parte de la consolidación de la economía algodonera, en febrero de 1926 se constituye en la Bolsa de Comercio de la Capital Federal, la Cámara Algodonera de Buenos Aires ${ }^{14}$. El objeto es: unir esfuerzos para mejorar las condiciones del negocio de algodón y defender los intereses de los productores, industriales y comerciantes algodoneros, tomando las medidas "que hagan eficaz el beneficio de la colectividad para el mayor desarrollo de los negocios", dice su Estatuto constitutivo. Promover la unión de los distintos centros, adoptando la conciliación de intereses para zanjar diferencias entre las partes; crear cámaras de arbitraje, "en pro de la solidaridad entre los gremios y en general entre los obreros y patronos"; presentar a las autoridades peticiones en beneficio de los gremios; estudiar y poner en práctica medidas que eviten las huelgas; procurar la entente entre las asociaciones, en beneficio de todos; y prestar ayuda moral y material a las autoridades y asociaciones en las iniciativas y actos encaminados a la protección y progreso del trabajo, de la industria y del comercio, son los objetivos de la entidad.

Integran la Cámara los diversos sectores vinculados al algodón: agricultores, acopiadores, comerciantes, transportadores, almacenadores, corredores, comisionistas, consignatarios, hilanderos, fabricantes de aceite y de tortas, y exportadores. Los socios — que pagan una cuota trimestral - se obligan a comprar o vender fibra únicamente sobre la base arbitral de la "Cámara Algodonera de Buenos Aires", y según las condiciones del boleto de compraventa, ésta quedará facultada para establecer oportunamente la admisión del sistema en otros centros del país ${ }^{15}$. A pesar de las mejoras en la comercialización, no faltan las quejas contra los acopiadores acusados de no pagar precios reales por el algodón a los colonos de Formosa y el Chaco ${ }^{16}$.

Desde el gobierno se insiste en considerar a Santiago del Estero como una zona inmejorable para el cultivo del algodón y proliferan los esfuerzos para intensificarlo y asegurar sus buenos rendimientos.

Bruniard (1975-1978), p. 67.

GA, Buenos Aires, julio 31 de 1927, año 2, núm. 42, pp. 22-29.

14 Miembros fundadores de la Cámara: Bunge y Born Lda., Louis Dreyfus y Cía., Cía. Gral. de Fósforos, Fábrica Argentina de Alpargatas, Bonifacio López, Bally Ltda.., J.V. Castaran, Valverde Lyon, B.F. Avery y Sons, Director de Gaceta Algodonera, Agar Cross y Cía., Möring y Cía., Cía. Algodonera del Río de la Plata, R. De Pamphilis, Armiño Ambrosetti, Herminio Cantu, Vicente Lambies, Lanata Hnos., Comercial Belgo Argentina, E. Pollackiek Cía., M. Comero Cía., Heriot y Cía., Niegel Bohom y Cía, Campomar y Soulas, , R. N. Del Sel Lda., Brach y Cía. Ind. del Quebracho, Lahusen y Cía. Lda., Santiago Scotto, Piccaluga y Ferrando. Comisión Directiva: Pte. Henry Mayer (Comercial Belgo Argentina), Vice Ing. F. Prati (Cía. Gral. de Fósforos), Secretario Bonifacio López y Tesorero Augusto Moring.

15 GA, Buenos Aires, febrero 28 de 1926, año 2, núm. 25, pp. 1-7.

16 Ibídem, mayo 31 de 1926, año 2, núm. 28, p. 11. 
Por entonces, la Asociación Fomento y Defensa del Chaco realiza gestiones ante el Ministerio de Agricultura y presenta un Memorial para contribuir al éxito de la colonización oficial en el territorio, alentando el cultivo algodonero. Solicitan conferencias de especialistas para asesorar a los colonos, promover la urgente selección de semillas, controlar los pesticidas utilizados por el productor y ampliar la red de ferrocarriles secundarios para intercomunicar las zonas productoras con las consumidoras. Propone, al mismo tiempo, mejorar la situación humanitaria del indígena; es decir:

"resolver las medidas conducentes a incorporar al indígena a la vida civilizada, haciendo de él un elemento útil en las cosechas de algodón, etc., estabilizándolo, esto es, acordándoles reservas de modo que puedan abandonar la vida nómade (Ley de Tierras 4167, art. 170), otorgándoles a los capacitados, tierras para cultivos, como lo han solicitado en persona, hace 3 años, el Cacique Chará y otros al Excmo. Señor Presidente de la República y al señor Director de Tierras, sin que hasta hoy se vean colmados los sanos propósitos de esos meritorios indígenas"17.

El documento declara una falta de 10.000 braceros en la cosecha y de allí deriva su interés por la incorporación del indio.

El auge de la producción algodonera se enlaza a la demanda progresiva de tierras fiscales, que deriva en una ocupación de las áreas disponibles generando una excesiva y poco redituable subdivisión de las zonas aptas para la explotación. La colonización se intensifica pero genera un minifundio en el mediano plazo, que impide la capitalización adecuada de los pequeños productores, endeudados y dependientes del acopiador local o del almacenero de campaña. Las cooperativas terminan, entonces, representando a los medianos y grandes productores.

En 1928 es la S.A. Bunge y Born — fuerte exportadora algodonera- la que anuncia la instalación de nuevas usinas desmotadoras de algodón en el territorio chaqueño ${ }^{18}$. No es la única empresa ligada a la exportación cerealera que instala desmotadoras algodoneras para consolidar su negocio. Un año más tarde, la S.A. Louis Dreyfus Lda. establece 4 desmotadoras en Charata (Chaco), dando muestras de la prosperidad del negocio algodonero. Promediando 1929 una delegación de industriales vinculados al sector se entrevista con el Presidente de la República y le solicita la ayuda oficial para limitar la competencia extranjera y alentar el consumo interno. En poco tiempo estas empresas y Anderson Clayton controlarían el 80\% de las desmotadoras chaqueñas y gran parte de la comercialización, desde la compra de algodón en bruto hasta el desmote. Una situación que los productores intentarán combatir —al igual que la regulación de precios- mediante el cooperativismo ${ }^{19}$.

En el decenio de 1930 el cultivo del algodón genera un intenso movimiento poblacional hacia la planicie centro chaqueña. Más que el fomento oficial, la recolección manual del algodón hace su aporte a esta concentración humana y esa mano de obra permanece en las colonias más tiempo que en el caso de otros cultivos ${ }^{20}$. La radicación de un alto porcentaje de esos braceros permite explicar el aumento en el número de chacras algodoneras y de la superficie cultivada. De los 12.559 agricultores algodoneros registrados en el Chaco, sólo 729 tienen título definitivo, 976 título provisorio, 2.400 ocupan campo ajeno y 8.454 campo fiscal $^{21}$. La

Ibídem, agosto 31 de 1926, año 2, núm. 31, pp. 24-25.

Ibídem, setiembre 30 de 1928, año 5, núm. 56, p. 8.

Para ampliar el tema: Mateo (2006) (2007) (2008).

Junta Nacional del Algodón (1936).

Bruniard (1975-1978), p. 69. 
calidad de "intrusos" en tierras fiscales hace depender al agricultor algodonero del préstamo del comerciante local, pues no puede acceder a los créditos oficiales que exigen garantía prendaria. Las cooperativas tienen un papel importante que jugar aquí, donde prima el monocultivo con escasa mecanización y menor tecnificación. No obstante, las hilanderías nacionales, afianzan su prosperidad económico-financiera ampliando sus instalaciones y maquinarias.

Los efectos de la crisis de 1930 se sienten en el empleo y el Estado Nacional es consciente de la situación. Desde 1932 lleva adelante un censo nacional de desocupados, como parte de un diagnóstico de la cuestión. Se crea la Junta Nacional para Combatir la Desocupación que desde 1935 emprende la tarea de redistribuir a los desempleados y clasificarlos, entendiendo que en la Argentina no hay desocupación sino mala distribución de los trabajadores, especialmente en el campo; donde ejerce su acción con resultados diversos ${ }^{22}$. La estadística da cuenta de la desigual distribución del cultivo algodonero como soporte para superar la crisis en el NEA (Cuadro 2) y también cómo con el correr del tiempo la tecnología no logra instalarse en la zona, más allá del uso de las desmotadoras (Cuadro 3).

CUADRO 2

NÚMERO DE CHACRAS Y SUPERFICIE CULTIVADA CON ALGODÓN (HECTS.). AÑO 1935

\begin{tabular}{lcc}
\hline \multicolumn{1}{c}{ Provincia o Territorio } & Número de chacras & Hects. cultivadas algodón \\
\hline Chaco & 13.673 & 245.625 \\
Corrientes & 5.074 & 24.078 \\
Santiago del Estero & 3.118 & 22.272 \\
Formosa & 2.030 & 12.240 \\
Santa Fe & 682 & 2.648 \\
\hline
\end{tabular}

Fuente: BRUNIARD, Enrique D. (1975-1978): "El Gran Chaco Argentino (ensayo de interpretación geográfica)", Geográfica. Revista del Instituto de Geografía 4, Resistencia (Chaco), Instituto de Geografía. Facultad de Humanidades de la Universidad Nacional del Nordeste, p. 67.

CUADRO 3

NÚMERO DE DESMOTADORAS DE ALGODÓN, 1923-1960

\begin{tabular}{lcccc}
\hline \multicolumn{1}{c}{ Provincias o Territorios } & Año 1923 & Año 1936-37 & Año 1946-47 & Año 1960-61 \\
\hline Chaco & 18 & 87 & 84 & 103 \\
Formosa & - & 4 & 7 & 12 \\
Santiago del Estero & 1 & 10 & 5 & 6 \\
Santa Fe & - & 4 & 8 & 13 \\
\hline TOTAL & 19 & 105 & 104 & 134 \\
\hline
\end{tabular}

Fuente: BRUNIARD, Enrique D. (1975-1978): "El Gran Chaco Argentino (ensayo de interpretación geográfica)", Geográfica. Revista del Instituto de Geografía 4, Resistencia (Chaco), Instituto de Geografía. Facultad de Humanidades de la Universidad Nacional del Nordeste, p. 77.

22 Departamento Nacional de Trabajo (1933). Junta Nacional para Combatir la Desocupación-Ley 11896 (1936). 
En los inicios de 1930, el Banco de la Nación Argentina a través de sus sucursales en Resistencia, Roque Sáenz Peña y Villa Angela del Chaco, accede al pedido de préstamo a los cultivadores de algodón, cuando colonos e instituciones agrarias solicitan tierras para cultivar y familias de agricultores se dirigen a zonas algodoneras ${ }^{23}$. Se arraiga con fuerza la constitución de cooperativas para beneficiar el trabajo del colono, con el propósito no sólo de "venderles la producción, sino también en adquirirle y entregarles los artículos de primera necesidad, es decir, alimentos y vestidos, máquinas de labranza, etc." ${ }^{24}$. Por entonces, el gerente de la empresa estadounidense Firestone Tire and Rubber Company anuncia la instalación en el país (Lavallol, provincia de Buenos Aires) de una gran fábrica de cubiertas de goma que consumirá más de 4.000 toneladas de fibra de algodón al año. En tiempos de crisis y desempleo, la industria algodonera es vista como una oportunidad laboral para más de 50.000 obreros ${ }^{25}$.

El 30 de octubre de 1935 el Banco de la Nación Argentina dispone - conforme a las pautas del Estado intervencionista- límites especiales de crédito para cooperativas con socios dedicados al cultivo algodonero. El interés anual es del 5\% (la cooperativa no puede exigir al colono más del $6 \%$ ) cuando la tasa ordinaria orilla el $7 \%{ }^{26}$.

Es en el Territorio Nacional del Chaco y para amparar a los productores algodoneros que se constituye en 1934 la Unión de Cooperativas Agrícolas Chaqueñas; una entidad de segundo grado que agrupa originariamente a 12 cooperativas de primer grado, con el objetivo principal de colocar el producto directamente en la Capital Federal, evitando que el productor dependa de los intermediarios que comercializan el algodón. Diez años más tarde son 31 las sociedades cooperativas algodoneras existentes en el país (24 de ellas en el Chaco), que agrupan a 8.313 socios, cuentan con un capital de $\$ 4.186 .315$ y realizan operaciones por \$ 37.637.50027. Algodón y cooperativismo marchan en paralelo desde muy temprano.

La creación, en 1935, de la Junta Nacional del Algodón concentra bajo su esfera de acción los aspectos inherentes a la producción, el comercio y el fomento de esta especie textil y oleaginosa. Se consolida su posición en el mercado interno, del cual dependerá en gran medida. Crece la tarea de divulgación e información para el colono y productor algodonero. La colección del Boletín Mensual (que se edita quincenalmente desde ese año) es una expresión de esta tarea que desde marzo de 1936 se complementa con la transmisión radiofónica de las cotizaciones del algodón, el censo algodonero de 1935-36, la aparición de Oro Blanco, una revista mensual de economía, vulgarización y tecnicismo dedicada al cultivo e industrialización del algodón que promueve los nexos entre los productores, los industriales y el gobierno, y una encuesta periódica que se hace a las hilanderías y tejedurías de algodón, para evaluar la situación del consumo.

GA, Buenos Aires,: enero 31 de 1930, año 6, núm. 72, p. 9; julio 31 de 1930, año 7, núm. 78, pp. 13-14. Ibídem, agosto 31 de 1930, año 7, núm. 79, pp. 9-10.

Ibídem, noviembre 30 de 1930, año 7, núm. 82, pp. 5-7; enero 31 de 1931, año 7, núm. 84, pp. 7-9; marzo 31 de 1931, año 8, núm. 86, p. 10.

Calvo (s/f), pp. 93-101 y 105-117.

Cavallone Brebbia (1947), pp. 119-126. En 1949 el Banco de la Nación Argentina forma una comisión especial para estudiar los requerimientos de los pequeños productores algodoneros del Chaco agrupados en 24 cooperativas agrícolas. El estudio realizado permite conocer en cifras las necesidades locales más urgentes, que están referidas a viviendas rurales y mecanización. En 1950 la entidad bancaria propone la formación de "núcleos agrarios pre-cooperativos", que pretende aprovechar el nucleamiento existente de los colonos de escasa o ninguna responsabilidad, situados en parajes aislados, para congregarlos en esas entidades societarias. Archivo del Banco de la Nación Argentina. Sección Carpetas Especiales (s/f), carpeta especial 313. 
El Ministro de Agricultura de la Nación -Miguel Angel Cárcano- es quien el 7 de junio de 1937 al inaugurar la primera desmotadora instalada en Catamarca, pregona la "múltiple acción del Estado" y su efecto multiplicador ante el avance de la economía algodonera en el Norte del país ${ }^{28}$. El Anuario Algodonero de 1938, registra una superficie sembrada con algodón para 1935-36 de 368.000 hectáreas y una producción de 80.957 toneladas de fibra cuyo precio promedio en Buenos Aires es de 985 pesos. El 78,8\% se los cultivos se radican en el Chaco.

Para abril de 1940, se considera "una medida de buen Gobierno en economía política y social, defender los precios de los productos de algodón" evitando la especulación ${ }^{29}$. Se constituye la Comisión de Adquisición de Fibra para las hilanderías de algodón, como otro paso para la organización de la economía algodonera, que le permita obtener un ventajoso apoyo crediticio oficial. En enero del año siguiente se organiza la Primera Gran Exposición del Chaco en el predio rural de Palermo. Es parte del avance del movimiento cooperativo en la zona algodonera, que impulsa la difusión de los telares a mano entre la "población pobre", promoviendo "un valioso estímulo para el trabajo manual de la juventud femenina" ${ }^{30}$.

En octubre del 41 el Poder Ejecutivo Nacional anuncia la creación en el Territorio Nacional del Chaco, de la Fábrica Nacional de Envases de Algodón ${ }^{31}$. En diciembre el Ministro de Agricultura visita varias localidades chaqueñas con el objeto de interiorizarse de la situación de la economía algodonera y el 17 de ese mes se crea la Corporación Argentina de la Tejeduría Doméstica, para canalizar por su intermedio los créditos especiales del Banco de la Nación destinados a promover la fabricación doméstica de tejidos. La Junta Nacional del Algodón propone sustituir el yute por el algodón en la fabricación de envases para artículos de producción nacional. Los considerandos del decreto de creación de la corporación, destacan la repercusión económico-social de esta iniciativa, al decir que:

"la tejeduría doméstica al desarrollarse en los propios hogares rurales robustece la unidad económica familiar permitiendo la colaboración de todos los miembros de la misma y constituye un tipo muy ventajoso de industria para ser fomentada en esas zonas ya que no daría lugar a la despoblación de la campaña ni a la aglomeración urbana, ni exigiría grandes desembolsos de capital en maquinarias e instalaciones" ${ }^{\prime \prime 2}$.

Al mismo tiempo, se contempla la necesidad de proveer a las familias de los elementos necesarios para esta actividad y al año siguiente se dispone adjudicar unos 600 telares caseros. El decreto del 29 de diciembre de 1942 tiene a su cargo la creación de Escuelas Fábricas Textiles, la redacción de sus planes de estudio y la organización de estos establecimientos, que dependen directamente de la Corporación ${ }^{33}$.

Oro Blanco (1936), año 1, núm. 3, pp. 5 y 14.

GA, Buenos Aires, marzo 31 de 1940, núm. 194, p. 1.

30 Ministerio de Agricultura de la República Argentina. Junta Nacional del Algodón, Boletín Mensual ${ }_{2}$ junio de 1940, núm. 62, pp. 254-256; agosto de 1940, núm. 64, pp. 364-374; diciembre de 1940, núm. 68, pp. 590-591; enero de 1941, núm. 69, p. 9; junio de 1941, núm. 74, pp. 449-450. GA, Buenos Aires, octubre 31 de 1940, año 17, núm. 201, p. 6.

31 GA, Buenos Aires, junio 30 de 1941, año 18, núm. 209, pp. 3-5; agosto 31 de 1941, año 18, núm. 211, pp. 1-2; setiembre 30 de 1941, año 18, núm. 212, p. 2; diciembre 31 de 1941, año 18, núm. 215, pp. 1-2.

32 Ministerio de Agricultura de la República Argentina. Junta Nacional del Algodón, Boletín Mensual, enerofebrero de 1942, núm. 81-82, pp. 5-7.

33 Ibídem, enero de 1943, núm. 93, pp. 45-46. Girbal-Blacha (2005), pp. 91-120. 
El 21 de julio de 1942, el Ejecutivo Nacional vuelve a intervenir en la economía y declara sujeta a expropiación hasta el $30 \%$ de la producción de hilados y tejidos de algodón y de mezcla de algodón, de todas las fábricas del país, pagando como indemnización la suma que resulte del margen de fabricación más el precio de adquisición de la fibra en cada caso ${ }^{34}$. Es para contrarrestar el desabastecimiento de telas para envases a causa de la conflagración mundial. A fines de ese año, cuando se firman nuevos convenios entre hilanderos y algodoneros para fijar sobreprecios por kilo de fibra de algodón consumida y se constituyen nuevas organizaciones cooperativas de colonos, la preocupación se hace extensiva a los miembros de la Asociación de Fomento de los Territorios Nacionales del Chaco y Formosa. Estos, junto a un grupo de desmotadores entregan al Presidente de la República sendos memoriales "con el fin de gestionar el apoyo del Poder Ejecutivo para solucionar algunos problemas relacionados con la economía del Chaco" ${ }^{\prime 35}$.

A mediados de la década de los 40 con una superficie sembrada de 381.914 hectáreas, la República Argentina figura en el mundo entre los 10 primeros países productores de algodón. Un $64 \%$ de la producción (unas 56.000 de las 72.350 ton. anuales) es empleado en la industria nacional ${ }^{36}$. Un nuevo convenio entre los hilanderos de algodón del país, pretende una vez más "defender y proteger los intereses de los productores de algodón del país, impedidos de poder colocar normalmente su producción como consecuencia de la difícil situación creada por las condiciones resultantes del conflicto bélico al cerrar los tradicionales mercados del exterior". El acuerdo es suscripto por las principales empresas textiles de la Argentina $^{37}$.

En 1945 el Banco de la Nación, como entidad que concentra gran parte del crédito agrario, mantiene los máximos prestables para la compra de semillas de algodón y su cultivo ${ }^{38}$. Sobre el monto prestado por el Banco a las cooperativas, las situadas en el Chaco reciben un 34,5\% del total. Los efectos de la Guerra Mundial favorecen la orientación de la producción algodonera hacia su industrialización interna que consolida la industria textil como parte del fortalecimiento de la capacidad de compra del mercado interno, y se complementa con las medidas que rápidamente adopta el gobierno peronista, retomando iniciativas previas. Es el caso de la Fábrica Nacional de Envases Textiles (inaugurada en setiembre de 1945) y la Corporación Argentina de la Tejeduría Doméstica, creadas para: fabricar envases para la producción agrícola, con la fibra de algodón de baja calidad ${ }^{39}$. La Fábrica es un auxilio indirecto a la industria textil privada, para colocar los saldos exportables de algodón y buscar salida al problema de los envases textiles y la industrialización de la materia prima en su zona productiva.

34

35

36

37

39 Ministerio de Agricultura de la República Argentina. Junta Nacional del Algodón, Boletín Mensual, setiembre-octubre de 1945, núm. 125-126, p. 392. La Fábrica Nacional de Envases se planea "con criterio científico y social en su ubicación y producción [...] para realizar lo que el país necesita", se afirma en su inauguración, para destacar "las ventajas de la descentralización industrial, no obstante que el noventa y cinco por ciento de las hilanderías se encuentran en la zona del Gran Buenos Aires". 
El decreto 12.589 de 1946 dispone la nacionalización definitiva de los envases textiles ${ }^{40}$. La Secretaría de Industria y Comercio:

"se proveerá de los tejidos que a tal objeto produzca la Corporación Argentina de la Tejeduría Doméstica, quedando facultada para emplear, por excepción, tejidos de otra procedencia nacional, toda vez que las necesidades de envases no alcanzaran a ser satisfechas por la citada Corporación" ${ }^{\prime 41}$.

La medida se complementa con otra del Ejecutivo Nacional, el 2 de mayo de 1947, que obliga a los industriales hilanderos de algodón a poner a disposición de la Secretaría de Industria y Comercio el 10\% de su producción de hilados, para colaborar con los industriales dedicados exclusivamente a tejeduría, que ven paralizadas sus fábricas por falta de materia prima $^{42}$.

El V Congreso Agrario Cooperativo, reunido en agosto de 1946, destaca que:

"las centrales cooperativas del Chaco y de Misiones, amparan en la acción común a los productores de algodón y de yerba mate, están haciendo algo más que una defensa de valores económicos, ya grande, y que se traduce en cifras impresionantes. Están creando un nuevo mundo moral en la vida de relación social, cuyos frutos son incalculables para el presente y el futuro de nuestro país, en cuanto están creando un nuevo espíritu que ha de acabar por eliminar el otro que ha permitido y permite la presencia de formas de la vida de relación, contrarias al mejor desenvolvimiento de la personalidad humana y que conspiran contra el mejor progreso de la Nación" ${ }^{43}$.

El Estado peronista no tardará en reconocer estos valores al cooperativismo imbricado en la expansión del cultivo algodonero casi desde sus orígenes. Para el gobierno se tornará imprescindible, luego de 1950, reducir los costos de intermediación y las cooperativas agrarias serán el instrumento en los tiempos del cambio de rumbo económico y con él "la vuelta al campo".

\section{Cooperativas agrarias en la economía marginal del Gran Chaco Argentino}

\subsection{El caso del algodón}

Las cooperativas algodoneras se organizan en el país de manera sistemática hacia 1919. Se funda entonces — sobre la base del intento de 1905- en el Chaco, la "Cooperativa Agrícola Algodonera Limitada de Margarita Belén", que por acción de la Junta Nacional del Algodón,

40 Para solucionar los problemas nacionales en pro del bienestar general; porque la producción de envases de algodón por el sistema de la tejeduría doméstica ha alcanzado un desarrollo suficiente para permitir al Estado encarar la nacionalización de los envases, para liberar a la producción de la dependencia externa; que la Corporación Argentina de Tejeduría Doméstica está en condiciones de proveer en número y tipos, bolsas para envases. Así se evita la especulación y se atiende al plan de recuperación que tuvo en vista la mencionada Corporación.

41 Ministerio de Agricultura de la República Argentina. Junta Nacional del Algodón, Boletín Mensual, mayojunio de 1946, núm. 133-134, pp. 159-160.

42 Ibídem, mayo-junio de 1947, núm. 145-146, p. 139. Girbal-Blacha (2005), pp. 91-120.

43 La Cooperación (LC en adelante), Buenos Aires, 16 de agosto de 1946, núm. 929, p. 3. 
primero, y de la Dirección del Algodón, después, promueve el movimiento cooperativo entre estos productores. Es la Oficina de Fomento de las Cooperativas Algodoneras - dependiente de esa Dirección - la que impulsa la educación cooperativa y los beneficios de este tipo de agremiación entre los agricultores del algodón.

Esta prédica favorable al cooperativismo hace posible la creación -en el Chaco- de la Unión de Cooperativas Agrícolas Chaqueñas Ltda., poco después denominada Unión de Cooperativas Agrícolas Algodoneras Ltda. En el artículo 3 de los Estatutos que la rigen declara sus fines: a) defender los intereses generales de sus asociados; b) propender al progreso técnico de la producción; c) implantar el seguro mutuo; d) comercializar e industrializar los productos de los asociados; e) importar máquinas para los asociados; f) otorgar créditos a las cooperativas adheridas; y g) fomentar el cooperativismo. Esta entidad cooperativa de segundo grado fundada en Roque Sáenz Peña, Departamento Napalpí del Chaco, el 17 de junio de 1934, dos decenios más tarde reúne a 20 cooperativas agrícolas algodoneras que aportan un capital superior a los 7 millones de pesos. La evolución de sus negocios se registra en su periódico "Ucal", que difunde su labor entre los asociados. En sencillo inferir la progresiva independencia del intermediario en la comercialización del algodón, que se canaliza por el sistema cooperativo que la entidad ofrece por medio de sus dos plantas textiles y una fábrica de aceite. Es una de las primeras organizaciones cooperativas que exporta directamente; en 1952 coloca 14.000 toneladas de algodón en el exterior, es decir, más del 50\% del volumen de este producto exportado entonces por la República Argentina ${ }^{44}$.

Al fomento institucional se suma la acción directa de la Sección Crédito Agrario del Banco de la Nación Argentina que hace llegar su apoyo financiero a las 31 cooperativas algodoneras (24 de ellas en el Chaco) que tiene la Argentina en 1945. Del total de cooperativas consignado, 20 de ellas siguen los pasos de la pionera "Cooperativa Agrícola Algodonera Ministro Le Bretón", y cuentan con desmotadoras propias; es decir, dominan un proceso que facilita al agricultor la percepción del valor real del producto conforme a la cotización oficial ${ }^{45}$. Un quinquenio después con una situación general estable, el número de cooperativas se mantiene. Una situación que no alcanza a producciones locales segmentadas como el tabaco y su manufactura.

Apenas iniciado1945 se reúnen los Delegados de las Cooperativas Algodoneras Argentinas, en la sala de reuniones de las Fábricas Nacionales de Envases Textiles. Convocados por ese organismo y por la Dirección del Algodón se proponen nombrar representantes de "auténticos agricultores", para dar cumplimiento a los decretos correspondientes de la Junta Nacional del Algodón y del Directorio de las Fábricas de Envases Textiles. Se tratan, además, problemas de actualidad económica: fijación del precio básico del algodón; provisión de vagones, con urgencia y en cantidad suficiente para el transporte de la semilla de algodonero destinada a la industria del aceite; provisión con tiempo de las cuotas de combustible para las desmotadoras de las cooperativas; habilitación urgente de los depósitos oficiales de fibra de algodón; y aumento del número de clasificadores oficiales de algodón en la zona ${ }^{46}$.

Por entonces, desde LRA Radio del Estado se inaugura un ciclo de conferencias del Instituto Agrario Argentino en colaboración con la Dirección del Algodón. Se sostiene allí, que el algodón es:

\footnotetext{
44 Grattarola (1954), p. 54. Yuri Izquierdo (1972), p. 122.

45 Cavallone Brebbia (1947), pp. 122-123.

46 Ministerio de Agricultura de la República Argentina. Junta Nacional del Algodón, Boletín Mensual, enerofebrero de 1945, núm. 117-118, pp. 30-31.
} 
“el único que ofrece amplias posibilidades para el desarrollo de la vasta y rica región del noreste argentino". [...] "En esas zonas de clima subtropical, no hay otro cultivo que presente como el algodón, las condiciones necesarias para servir de base al desarrollo de la agricultura, haciendo pleno uso de la tierra laborable que existe disponible y dando ocupación abundante a los trabajadores rurales". [...] "Es una realidad económica que el algodón es el producto básico de la economía del noreste argentino y lo será por muchos años, dada la escasez de condiciones con que cuentan los demás cultivos que podrían servir para la diversificación y las dificultades que se presentan al Estado para promover, con un plan de plazo breve, el mejoramiento de esas condiciones en forma tal que estos otros cultivos ofrezcan al productor las mismas perspectivas de resultado económico" ${ }^{\prime 7}$.

En 1947 el porcentaje de capital aportado por las cooperativas algodoneras al conjunto, es del 17,05\% y desciende en 1951 a un 15,49\%, cuando el gobierno nacional cambia el rumbo de la economía y privilegia la producción agropecuaria de la pampa húmeda. Son múltiples los ejemplos del significado que representa el cooperativismo en la economía algodonera del Nordeste argentino ${ }^{48}$. En algunos casos la adecuación a las circunstancias del mercado se convierte en un aliado del progreso de estas entidades. Sucesivos créditos del Banco de la Nación Argentina de entre uno y tres millones de pesos, para ser devueltos hasta en 10 años con un interés del $5 \%$ anual, consolidan el accionar cooperativo ${ }^{49}$.

La División de Cooperativas de la Secretaría de Industria y Comercio informa en 1948 acerca del desarrollo cooperativo en la Argentina. Chaco (27 cooperativas) y Misiones (16 cooperativas) figuran en los primeros lugares en cuanto a la representación cooperativa. Con relación al capital suscripto, Chaco concentra \$ 4.737.740; en tanto en el monto de operaciones, ocupa el quinto lugar con \$32.296.214. Por estos años, de los 900 organismos cooperativos, 154 son cooperativas agrícolas; 30 algodoneras (con 8.353 socios, el capital suscripto $\$ 4.328 .004$ y el monto de las operaciones realizadas alcanza a \$ 31.952.365); 99 de consumo; 91 de crédito; 107 de electricidad; 14 de seguros urbanos; 6 de seguros rurales; 261 tamberas; 71 varias urbanas; 23 varias rurales; 28 vitivinícolas, frutícolas y hortícolas; 16 tabacaleras y yerbateras ${ }^{50}$.

Desde 1950 el movimiento cooperativo se fortalece, con el auspicio gubernamental ante la necesidad de disminuir los costos de intermediación y el Banco de la Nación Argentina redobla su oferta crediticia en condiciones especiales, dirigidas al sector. También el Banco de Crédito Industrial Argentino da a conocer en enero de 1951, una resolución que acuerda préstamos especiales para desmotadoras particulares independientes de algodón, es decir, las que trabajan usinas propias y no son propiedad de exportadores, hilanderos o cooperativas del ramo. El propósito es facilitar la evolución de estas firmas (Cuadro 4$)^{51}$.

El mayor éxito del cooperativismo algodonero corresponde al aspecto comercial. Es menor su avance en la organización racional del cultivo y en la industrialización directa de las cosechas de algodón o en la asociación de capitales para extender los beneficios de la mecanización de las explotaciones (especialmente de las pequeñas). En 1950 la presidencia de la Cámara Algodonera recae una vez más en el representante de la Unión de Cooperativas

47 Ibídem, mayo-junio de 1945, núm. 121-122, pp. 223-226.

48 Girbal-Blacha (2003), cap. IV.

49 Archivo del Banco de la Nación Argentina (ABNA en adelante): Libro de Actas del Directorio, setiembre 1947, t. 32, f. 30; junio 1948, t. 66, f. 33; diciembre 1948, t. 92, f. 66; noviembre 1949, t. 134, fs. 197-198; agosto 1950, t. 169 , f. 26; enero 1952 , t. 224 , f. 109.

$50 \quad$ LC, Buenos Aires, 7 de mayo de 1948, núm. 1017, p. 3.

51 Ministerio de Finanzas de la Nación. Banco de Crédito Industrial Argentino (1952), pp. 75-81. 
Agrícolas Chaqueñas, quien también es miembro del Directorio de la Bolsa de Comercio y vicepresidente del Mercado del Algodón. Otros 2 representantes de cooperativas: "El Progreso" y "Unión y Progreso", son vocales en la comisión directiva; todas ellas con actuación en el territorio del Chaco. El cooperativismo chaqueño se siente valorizado y destaca su importancia al decir que" no se limitó a extraer el algodón en bruto de las chacras para ponerlo en los depósitos, sino que de inmediato casi, montó sus usinas desmotadoras y vino al mercado de Buenos Aires para defender el valor de la producción, sin necesidad de entregarla a los comercializadores extraños al movimiento". El reclamo ante el Estado no se hace esperar y la Cámara le pide que "permita la libre exportación de la mercadería otorgándole un cambio especial para poder competir en el exterior convenientemente" 52 .

Por entonces, la Unión de Cooperativas Agrícolas Chaqueñas, que reúne unas 20 cooperativas agrarias del territorio ${ }^{53}$ — cuando en el país se registran unas 29 cooperativas algodoneras - cuenta con un capital social totalmente realizado (\$2.957.200) y declara haber vendido fibra de algodón por un valor superior a los 92 millones de pesos; una actividad que completa con la venta de productos a sus asociados por un valor superior a los 5 millones y medio de pesos. Su activo total suma $\$ 10.233 .615,57$, el pasivo no exigible, capital accionario y fondos de reserva y previsión asciende a $\$ 3.179 .243,02$ y el exigible es de $\$ 6.413 .205,46$. Su prosperidad no es sólo económica; además "cumple una intensa acción de asistencia societaria que va más allá de la simple parte económica para extenderse en la atención de los intereses de los socios de las cooperativas afiliadas, sobre todo en Sáenz Peña y Buenos Aires" ${ }^{\prime 5}$.

En octubre de 1952 cinco cooperativas exportan a Gran Bretaña 8.000 toneladas de algodón. Los representantes presentes en la firma del documento son delegados de la Asociación de Cooperativas Argentinas (ACA), de la Unión de Cooperativas Agrícolas Chaqueñas, de la Cooperativa Agrícola Unión y Progreso (de Presidente de la Plaza), de la Cooperativa Agrícola Ministro Le Bretón y de la Cooperativa Agrícola de La Banda (Santiago del Estero) ${ }^{55}$. Dos años más tarde las ventas de fibra de algodón por un total de $\$ 8.650 .803,61$, se distribuyen entre diversas cooperativas de la región chaqueña ${ }^{56}$. El Banco de la Nación Argentina refuerza sus préstamos y concreta concesiones especiales ${ }^{57}$.

Cobijada por la acción del Estado peronista, eleva el resultado de su primer ejercicio operativo la Cooperativa Agrícola "La Justicialista", de Las Breñas (Chaco). El excedente de \$ 16.414,14 es módico, pero su acción resulta importante para los colonos, mantenidos hasta entonces "en una situación de humillados, obteniendo la entidad agrupar en su seno, a más de 400 productores ${ }^{\prime \prime 5}$. Aspectos económicos y sociales dan sustento a un indudable rédito político sostenido desde el oficialismo.

3 Integran la central cooperativa: Cooperativa Agrícola de Sáenz Peña; Cooperativa Agrícola El Progreso; Cooperativa Agrícola de Machagay; Cooperativa Agrícola de Charata; Cooperativa Agrícola La Unión; Cooperativa Agrícola de Castelli; Cooperativa Agrícola de Tres Isletas; Cooperativa Agrícola de Presidencia de la Plaza; Cooperativa Agrícola de Quitilipi; Cooperativa Agrícola Ideal; Cooperativa Agrícola La Defensa; Cooperativa Agrícola de Makallé; Cooperativa Agrícola El Triunfo; Cooperativa Agrícola de Colonia Elisa; Cooperativa Agrícola de Colonias Unidas; Cooperativa Agrícola de El Zapallar; Cooperativa Agrícola de Las Garcitas y Cooperativa Agrícola de Villa Angela.

54 LC, Buenos Aires, 6 de abril de 1951, núm. 1164, pp. 1 y 3. Mateo (2006).

55 LC, Buenos Aires, 18 de octubre de 1952, núm. 1243, p. 2.

56 LC, Buenos Aires, 26 de marzo de 1954, núm. 1317, p. 1.

57 Archivo del Banco de la Nación Argentina: Libro de Actas del Directorio, noviembre 1952, t. 255, f. 112.

58 LC, Buenos Aires, 18 de junio de 1954, núm. 1329, p. 4. 
Las preocupaciones para favorecer el buen funcionamiento de las entidades cooperativas de las áreas marginales se manifiestan en el Norte de Santa Fe, a través de una importante reunión de estas sociedades afiliadas a la ACA. Se lleva a cabo en agosto de 1954 y participan los productores locales, los agrónomos regionales y funcionarios, para discutir los problemas derivados de los cultivos de algodón, lino, maíz, girasol y caña de azúcar, en relación con asuntos agronómicos, su vinculación con el crédito bancario y la posibilidad de establecer una aplicación industrial de estos cultivos, conforme a los planes que lleva adelante la Asociación de Cooperativas Argentinas ${ }^{59}$. Se sostiene allí que recién en 1953 los asociados a estas cooperativas algodoneras santafesinas entregan la totalidad de su producción a esta entidad de segundo grado, para su comercialización. En una época de mercados flojos:

"la Asociación de Cooperativas Argentinas asume la responsabilidad de defender los intereses de los productores, hasta ayer dependientes de intermediarios que, con su actuación, no habían sabido satisfacer las legítimas aspiraciones del agricultor"60.

La totalidad de la producción obtenida en esa campaña $(3.012 .960 \mathrm{~kg}$. de fibra de algodón), es comercializada por la entidad por un valor de \$22.009.677,56. La gestión de la ACA en la comercialización del algodón, es sólo un aspecto de las ventajas de un sistema que se aplicará en la comercialización total de la producción del campo:

"para que, definitivamente, desaparezcan del escenario rural, las organizaciones capitalistas que alimentadas por el campo, impidieron su desarrollo y su progreso efectivo, porque convenía al acopiador la necesidad y la miseria del productor, que así tenía, irremediablemente, que caer bajo su dominio" ${ }^{\prime \prime 1}$.

CUADRO 4

PRÉSTAMOS OTORGADOS EN EL CHACO POR EL BANCO DE LA NACIÓN ARGENTINA

Y EL BANCO DE CRÉDITO INDUSTRIAL ARGENTINO, 1945-55 (MILLONES DE M\$N)

\begin{tabular}{ccccc}
\hline \multirow{2}{*}{ Año } & \multicolumn{2}{c}{ Banco Nación Argentina } & \multicolumn{2}{c}{ Banco Crédito Industrial Argentino } \\
\cline { 2 - 5 } & Total general & $\mathbf{m} \$ \mathbf{n}$ en Chaco & Total general & m\$n en Chaco \\
\hline $\mathbf{1 9 4 5}$ & $1.135,9$ & 50,5 & $131.787,5$ & 562,3 \\
$\mathbf{1 9 4 8}$ & $5.522,8$ & 49,4 & $1.460 .562,5$ & $9.834,0$ \\
$\mathbf{1 9 5 0}$ & $8.019,9$ & 129,9 & $2.148 .712,5$ & $87.067,8$ \\
$\mathbf{1 9 5 2}$ & $13.256,3$ & 364,2 & $2.951 .940,4$ & $65.287,2$ \\
$\mathbf{1 9 5 5}$ & $28.243,9$ & 338,9 & $4.869 .194,5$ & $93.598,7$ \\
\hline
\end{tabular}

Fuente: Poder Ejecutivo Nacional. Secretaría de Estado de Hacienda (1958): Anuario estadístico de la República Argentina, 1957, Buenos Aires, Dirección Nacional de Estadística y Censos. Elaboración propia.

${ }_{59}$ LC, Buenos Aires, 3 de septiembre de 1954, núm. 1340, p. 1.
60 LC, Buenos Aires, 15 de octubre de 1954, núm. 1346, p. 1.
${ }_{61}$ LC, Buenos Aires, 15 de octubre de 1954, núm. 1346, p. 1. 


\subsection{El tabaco o una experiencia agraria no cooperativa}

Los cultivadores tabacaleros en el Norte de la Argentina, es decir los que actúan en casi un $20 \%$ del territorio nacional, son los protagonistas invisibles de una industria manufacturera rica y concentrada, la del cigarrillo, los cigarros y sus derivados. Un área territorial que aun en los años de 1920 registra denuncias ante la policía de malones de tobas y matacos que habitan en tolderías, llevan una vida nómade y son acosados por el avance de "los hacendados fuertes, sociedades anónimas y comerciantes"; en síntesis, por quienes procuran explotar el bosque, el algodón, la yerba mate y también el tabaco ${ }^{62}$.

A propósito del "fomento del Norte Argentino", en julio de 1930, los Presidentes de Brigada de la Liga Patriótica Argentina (entidad nacionalista de elite creada en 1919), manifiestan su decisión de "unir sus esfuerzos en pro del mejoramiento de las industrias de cada zona", con la intención de que sus consideraciones pasaran a estudio de la Comisión de Asuntos Sociales. Es ésta la que informa entonces - con extrema simpleza - que la crítica situación social norteña puede contrarrestarse con "la creación de Sociedades de fomento que la Liga Patriótica Argentina, por intermedio de sus numerosas Brigadas, auspiciaría en los centros más apartados de la República". La entidad confía en que la unión de estos pobladores es una tarea fundamental para evitar el aislamiento y con él sus nefastas consecuencias para el progreso socioeconómico regional. Una vez más la institución nacionalista apela al "patriotismo y la integridad moral" de los pobladores para superar situaciones críticas, que poco consideran el precario nivel de vida de las familias del lugar ${ }^{63}$.

Postergaciones, pobreza, largas jornadas de trabajo sin distinción de edades ni género y condiciones de vida difícilmente cercanas a la media del país, son las características del cultivo y producción del tabaco en el Norte argentino. No obstante, hacia 1928 las 7 sociedades anónimas tabacaleras nacionales declaran un porcentual de ganancias sobre el capital efectivo del 11,73\%, ocupando el quinto lugar luego de las dedicadas a explotaciones forestales, materiales de construcción, curtiembres y fabricantes de bolsas ${ }^{64}$.

Un clima de tensiones cobra cuerpo en este espacio del territorio, dando origen a una compleja situación en la red de relaciones socioeconómicas, que merece ser estudiada, aunque la documentación sea escasa y dispersa. Es importante poder diagnosticar el contraste de estado de situación lejano a la prosperidad de los comerciantes y manufactureros del tabaco, para comprender que aun en el mismo espacio, algodón y tabaco tienen códigos operativos diferentes.

En la Argentina el cultivo del tabaco no tiene límites para su producción y cultivo. No se requiere autorización previa para hacerlo. Sólo depende de las condiciones ambientales, climáticas y de la calidad del suelo. De todos modos, el Estado ejerce un control, por lo general, con fines estadísticos y fiscales. También cumple con su papel orientador a los cosecheros, pero lo hace, esencialmente, para seguir los distintos estadios de este producto desde la plantación hasta la manufactura ${ }^{65}$.

Es por razones fiscales que la reglamentación impositiva establece en su artículo $1 .^{\text {o: }}$

62 Archivo Histórico del Chaco (AHCh en adelante) (1921): Territorio El Pintado. Comisión de Fomento, 19191949. Folio 418, letra P. Material sin catalogar. Scobie (1988), pp.48-74. Para un análisis minucioso de los productores tabacaleros ver: Girbal (2007), pp. 83-105.

63 Revista de Economía Argentina, Buenos Aires, julio de 1930, año 13, tomo XXV, núm. 145, pp. 97-98.

64 Ibídem, Buenos Aires, diciembre de 1929, año 12, tomo XXIII, núm. 138, p. 479.

65 Girbal-Blacha (2008), pp. 49-75. 


\begin{abstract}
"los cosecheros tienen la obligación de inscribirse en la Administración General de Impuestos Internos. Con ese fin remitirán a la seccional o distrito de la jurisdicción donde se encuentran las plantaciones, una comunicación que contendrá las siguientes referencias y que se hará en formulario oficial gratuito" ${ }^{66}$.
\end{abstract}

En dichos formularios debe constar el nombre y apellido del cosechero, así como la ubicación precisa del lugar dónde se sitúan las plantaciones. Una información que se anotaría en el libro de empadronamiento zonal, enviando constancia de esa inscripción al cultivador. Son ellos quienes - a su vez- deben informar anualmente (entre diciembre y enero) a la Administración de Impuestos, sobre el estado de sus plantaciones, indicando la clase de semilla empleada y el rendimiento probable de la cosecha de tabaco (Cuadro 5).

\title{
CUADRO 5
}

RECAUDACIÓN DE IMPUESTOS INTERNOS SOBRE PRODUCTOS TABACALEROS NACIONALES E IMPORTADOS (M\$N)

\begin{tabular}{cccrc}
\hline Año & Cigarrillos & Cigarros & Tabaco y rapé & Total \\
\hline $\mathbf{1 9 1 0}$ & $13.478 .201,94$ & $4.794 .774,03$ & $5.018 .018,87$ & $23.290 .994,84$ \\
$\mathbf{1 9 1 5}$ & $19.641 .877,69$ & 5.645 .226 .42 & $6.906 .957,52$ & $32.194 .061,63$ \\
$\mathbf{1 9 2 0}$ & $33.497 .781,97$ & $5.884 .103,83$ & $5.976 .104,00$ & $45.357 .989,87$ \\
$\mathbf{1 9 2 5}$ & $41.699 .166,27$ & $6.749 .791,34$ & $6.908 .034,73$ & $55.356 .992,34$ \\
$\mathbf{1 9 3 0}$ & $48.942 .356,23$ & $6.660 .215,74$ & $7.217 .374,44$ & $62.819 .946,41$ \\
$\mathbf{1 9 3 6}$ & $77.764 .654,33$ & $7.761 .333,09$ & $10.147 .637,94$ & $95.673 .625,36$ \\
\hline
\end{tabular}

Fuente: Administración General de Impuestos Internos (1937): Memoria correspondiente al año 1936, Buenos Aires, p. 34

El empadronamiento de cosecheros es trienal. La función del empadronamiento es mantener los datos actualizados de los cosecheros de tabaco y sólo quedan exceptuados de hacerlo quienes produzcan menos de 500 kilos anuales. Estos padrones serían entregados a los comerciantes, para que compren a los empadronados, evitando el contrabando. Estos tabacos son los que la ley admite como de libre circulación dentro de la zona a la cual pertenecen. Por otra parte, los cosecheros que enfardelan tabaco (Ley 12148) por cantidades superiores a los $20.000 \mathrm{~kg}$ son considerados legalmente comerciantes y —en consecuencia - tienen que cumplir con los requisitos que esta condición conlleva.

La ley precisa un contralor mutuo, que no siempre se practica, esencialmente en las regionales productoras de la materia prima, distanciadas de los centros manufactureros. La acción económica del Estado en materia tabacalera no es tan eficiente como la fiscal, tratándose de una producción que aporta una renta equivalente a la décima parte del presupuesto nacional pero que además da sustento a numerosos agricultores, obreros y empleados de las manufacturas y comercio de tabacos. De ahí el cultivo mayoritario de tipos criollos de escasa calidad y poco valor, en cantidades mayores a las que puede absorber el mercado interno y sin que resulte posible exportarlo. Los tabacos de calidad se importan. La crisis productiva y la miseria de los productores no son ajenas a una presencia estatal discontinua y desigual. En este contexto el cooperativismo no tiene cabida, ni cultural ni materialmente. 
En mayo de 1934 el gobernador del Chaco procede a solicitar al comisario de policía de Resistencia el registro cuidadoso de la nacionalidad, el carácter de ocupante de las tierras fiscales (título provisorio, definitivo u ocupación de hecho) y el número de lote de quienes son percibidos como dirigentes del movimiento de huelga agraria de Las Breñas. Los 16 extranjeros que la lista registra, con apellidos ucranianos, polacos y checoslovacos, muestran una vez más la precariedad de las relaciones laborales y la interferencia política en la resolución de los problemas socio rurales ${ }^{67}$.

El censo tabacalero levantado en 1935 consigna 12.506 cosecheros inscriptos (7006 en Misiones y 3953 en Corrientes), el área sembrada con tabaco supera las 20.630 hectáreas en todo el país - con alta concentración en los territorios mencionados- y los kilos de tabaco producido totalizan los 25.355.486, calificados en su estado general como regular.

En agosto de 1937 la Asociación de Cosecheros, Comerciantes y Manufactureros de Tabaco acciona ante el gobierno nacional para obtener habilitaciones portuarias destinadas a la importación y exportación de tabaco en hoja y picadura. La conciliación de intereses da muestras de la concentración productiva en torno a la industrialización de la materia prima; a pesar de las funciones de la División Tabacalera, donde se sostiene "que una acción bien orientada para el fomento de este cultivo, debe contemplar no solamente las necesidades de la industria, sino también asegurar mayores beneficios a los agricultores" ${ }^{\prime 68}$.

Estas medidas que procuran mejorar la producción, son insuficientes para elevar el nivel de vida de los productores y sus familias, ya que los precios remuneradores para el cultivador no resultan de resultado inmediato ${ }^{69}$. Paul Chaussette dirá que en la Argentina se necesita "una legislación de organización del trabajo", para "prever y suprimir los abusos patronales desarrollando al mismo tiempo un programa de educación industrial a base de la cooperación intima y razonada entre el capital y el trabajo"70.

En 1938, el Instituto Agrario Argentino, en contacto con el Gobernador chaqueño José Castells, también se congratula de las informaciones agrarias que propala por la estación de radio Fénix de Buenos Aires, tocando "temas diversos de interés cultural para los agrarios del país", pero la prédica parece no llegar a los tabacaleros de la región a la hora de orientar las mejoras de su producción.

El costo de producción de una hectárea de tabaco criollo en Corrientes es de \$218,25 y en Misiones de \$242,50; mientras el rendimiento medio por hectárea es de $1.500 \mathrm{~kg}$ y con un precio de venta de $\$ 0,40 \mathrm{el} \mathrm{kg}$ que hacen un total de $\$ 600$, en el primer caso; y de $1.300 \mathrm{~kg}$ en el segundo caso, con similar precio de venta por $\mathrm{kg}$, que hacen un total de \$520. Estos guarismos se deterioran para el caso de Catamarca, en el Noroeste del país ${ }^{71}$.

En marzo de 1940 se realiza en el Chaco la primera reunión de la Comisión Territorial de Braceros como parte de las acciones llevadas a cabo por la Junta Nacional para Combatir la Desocupación creada en 1932. En 1935 son los braceros para la cosecha de algodón quienes ocupan la atención de esta Junta para los casos de Corrientes, Santiago del Estero y el Chaco. La distribución de brazos intenta concretar la regulación del trabajo de manera progresiva y conforme a los postulados de la Argentina intervencionista de los años 30. Pero los cultiva-

67 AHCh: Época Territorial. Gobernación del Chaco. Notas enviadas (Huelgas Agrarias), años 1933, 1934, 1936 y 1938 Caja 21.1, fs. 1-37, mayo 15 de 1934.

68 Decreto 99394 de 1937.

69 Daneri, Manuel J. (1938), p. 121.

70 Revista de Economía Argentina, Buenos Aires, octubre de 1937, año 19, tomo XXXVI, núm. 232, p. 275.

71 Daneri, Manuel J. (1938), p. 127. 
dores tabacaleros ni siquiera son tenidos en cuenta a la hora de analizar la situación social por la que atraviesan, el trabajo de menores y la jornada legal ${ }^{72}$.

Con la vigencia del Estatuto del Peón Rural desde 1944, los reclamos para obtener mejores condiciones de trabajo en el campo se hacen presentes con frecuencia. De todos modos los pedidos en tiempos del peronismo — desde 1946 - para obtener la creación de escuelas granja, escuelas de artes y oficios, sindicalización de la mano de obra en áreas rurales, como parte del "bien general e identificados en el supremo ideal de lograr una Argentina fuerte, soberana y justa", si bien atrae a los algodoneros — por ejemplo- no parece incluir de modo específico a los productores y cosecheros tabacaleros, vale decir:

"un gran porcentaje de población eminentemente criolla no sólo desposeída de bienes materiales sino de capacitación general para trabajar y como para otra defensa en la lucha por la vida. No se puede olvidar que el régimen tuvo siempre una sola preocupación capital: embrutecer el elemento nacional y dividirlo para mejor mantenerse en el poder"73,

sostiene la Delegación Regional de la Confederación General del Trabajo desde Villa Angela (Chaco).

$\mathrm{Si}$ es frecuente encontrar advertencias al productor tabacalero, para que "esmere todo su tratamiento para hacer valer su producto", así lo aconsejan los técnicos de la Dirección de Tabaco, mientras ofrecen un asesoramiento que ignora las condiciones laborales de productores y cosecheros de esta materia prima, quienes sí tienen la obligación de registrarse en la Dirección mencionada $^{74}$. En 1945 el Boletín del tabaco — por ejemplo- se ocupa de las condiciones ecológicas de la producción tabacalera pero no ensaya un análisis de las condiciones paupérrimas en que se desempeña el productor o el cosechero de tabaco. Tampoco le propone la acción cooperativa. Sólo le propone clasificar el producto para obtener una mayor compensación y una más eficiente comercialización. La "defensa del cultivo", las "instalaciones adecuadas" son las preocupaciones principales de técnicos oficiales y empresarios, a pesar de que en provincias como la de Corrientes existe un 33,35\% de arrendatarios y un 32,59\% de aparceros dedicados al cultivo tabacalero ${ }^{75}$. La colonización, la construcción de viviendas dignas y el crédito adecuado para estos sectores, son aun para fines del decenio de 1940, materias pendientes.

En tiempos del peronismo se reconoce que 60.000 familias agricultoras pueden obtener su medio de vida en el cultivo del tabaco, a pesar de los dos problemas esenciales que deben atenderse: 1) defender la economía del productor, y 2) tecnificar el cultivo. En agosto de 1946 la revista La Chacra publicaba que mientras la industria manufacturera del tabaco se lleva $\mathrm{m} \$ \mathrm{n} 20.000 .000$ y a los intermediarios recaudan $\mathrm{m} \$ \mathrm{n} 90.000 .000$, los productores reciben $\mathrm{m} \$ \mathrm{n}$ 9.000 .000 al año. Cifras que "dan la pauta del estado lamentable de nuestra situación tabacalera en el aspecto económico-social"76.

72 Gobernación del Chaco de la República Argentina (1937), pp. 91-102.

73 AHCh: Territorio Villa Angela. Municipalidad, 1936-1946. Caja núm. 2. Villa Angela, diciembre 19 de 1946, sin foliar. Material sin catalogar.

74 Secretaría de Industria y Comercio (SIC en adelante). Dirección de Tabaco (1946), contratapa.

75 SIC. Dirección de Tabaco: Boletín del tabaco (en adelante BT), Buenos Aires, enero marzo de 1947, año XI, pp. 15-16.

76 La Chacra, Buenos Aires, Editorial Atlántida, agosto de 1946, p. 75; febrero de 1948, p. 71 (en este caso para Corrientes). 
Por entonces, las compensaciones más frecuentes se destinan a los fabricantes de tabacos económicos, en el marco de la regulación del mercado, "mediante la neutralización de los factores que tornan antieconómica la explotación", especialmente cuando son consumos destinados a sectores de la población que cuentan con bajos recursos. Así lo dispone, por ejemplo, el decreto 21736 del 24 de julio de $1947^{77}$. A la hora de acreditar los tabacos nacionales una vez más se apela al agricultor y al cosechero para que clasifique adecuadamente sus hojas de tabaco, evitando así que el manufacturero deba hacer una reclasificación ${ }^{78}$.

Los tipos de cooperativas existentes en 1948-49, cuando se reorienta la economía argentina, expresan la gran variedad de actividades que están a su cargo. Las más importantes por su número — se radican en la región pampeana - son las tamberas: 369; agrícolas 225; vinifrutícolas-hortícolas 32; algodoneras 29; yerbateras y tabacaleras 19; ganaderas 15; granjeras 13; abastecimiento de carnes 11; de productos lácteos 6 . En tanto las cooperativas de consumo totalizan 165; las de electricidad 153; de crédito 101; de seguros 21; de transportes 20; de vivienda 10; automóviles y afines 8 y en rubros diversos 52. El cooperativismo agrario representa el 65\% del valor de las operaciones de conjunto (Cuadro 1).

Proliferan las denuncias ante el Ministerio del Interior desde alejadas regiones rurales del Nordeste — como Avia Terai y Napenay (Chaco) — hacia 1949, por huelgas de obreros y colonos rurales, acusados de ser comunistas. Quienes una vez investigados resultan ser "auténticos cultivadores de la tierra"79. Son tirantes las relaciones entre productores, cosecheros y obreros del campo con algunas de las Comisiones de Fomento locales, en medio de trabajos transitorios que propician esas reacciones. El control ejercido por "el largo brazo" del Estado peronista, también llega a estas apartadas regiones del país y lo hace dando consejos prácticos a cosecheros y agricultores de tabaco desde la Dirección respectiva.

Entre enero y marzo de 1949, la Comisión Nacional de Trabajo Rural es la que establece salarios y condiciones para las tareas de la cosecha de tabaco en la provincia de Jujuy y también las remuneraciones de los menores (entre 12 y 17 años) ocupados. Es una regulación - aunque circunscripta administrativamente- concreta, al momento de regir la relación entre patrones y trabajadores tabacaleros. Si bien se pena a los patrones por el no cumplimiento de la normativa, también se advierte que "los diferendos que se susciten no podrán dar lugar a la paralización del trabajo" ${ }^{\prime 80}$.

En 1957 se reúne en Las Breñas (Chaco) el Sindicato de Productores Agropecuarios. Las deliberaciones son interesantes como ejemplo de la inestabilidad del sector y la dispersión en los temas que los ocupan. En primer término el interés se sitúa en el informe de los delegados al 45 Congreso de la Federación Agraria como parte del accionar de la Unión de Cooperativas del Chaco, pero que sólo atiende a los problemas algodoneros, no de otras producciones regionales, como es el caso del tabaco; dando muestras de las distancias que separan al gremio de braceros. Una situación que lleva a exigir al Sindicato la creación de escuelas hogares en el campo, entendiendo que las injusticias que sufren el peón y los productores rurales, forman parte del "bajo nivel cultural que hay en el campo". La formación de la subcomisión de braceros ocupa el tercer tema de la reunión y su misión es tan acotada como poco efectiva, ya que es su tarea "gestionar los pasajes gratis para el cosechero al venir a trabajar y para su

77 SIC. Dirección de Tabaco: BT, Buenos Aires, julio-setiembre de 1947, año XI, pp. 57-59.

78 SIC. Dirección de Tabaco: BT, Buenos Aires, enero marzo de 1948, año XII, p. 40.

79 AHCh: Territorio Avia Terai. Comisión de Fomento, 1926-1951. Caja núm. 1, marzo 3 de 1949, fs. 459 y afiche del Comité local del Partido Comunista.

80 Anales de Legislación Argentina (1949), pp. 1184-1185 y 1239. 
regreso el 50\% de rebaja", asegurando "albergue por un día y comida hasta que sean trasladados a los lugares de trabajo" ${ }^{81}$.

Al promediar la década de 1950 las convenciones colectivas de trabajo rigen para el personal de la industria del tabaco, pero no para quienes se dedican al cultivo o a la cosecha. Los sectores más empobrecidos parecen no tener acceso a la "justicia social". Sólo los precios mínimos al productor se aseguran gubernamentalmente, aun al inicio de los años 60 . Por entonces es indiscutible el mayor desarrollo tabacalero correntino, cuando para esa década del Instituto Provincial del Tabaco registra 1.300 productores minifundistas, unos 3.000 aparceros con superficies de entre 2 y 3 hectáreas y unos 2.300 ocupantes precarios de tierras de otros propietarios, sobre un total de 7.200 productores tabacaleros. Estas explotaciones reducidas - con una producción de entre 800 y 1.000 kg por hectárea- mantiene a los plantadores y cosecheros de tabaco en un nivelo de subsistencia. No se advierten mejoras técnicas significativas y tampoco inversiones ponderables, por lo cual las modalidades de pago del sistema cooperativo son poco viables y termina imponiéndose aun el trueque con los bolicheros locales.

\section{Conclusiones}

Los avances operados en el cultivo y la industrialización del algodón en la región del NEA, ocurrieron al amparo de la protección estatal, del crédito bancario oficial, de la diversificación inversora de los capitalistas de la pampa húmeda y del eje metropolitano, así como del accionar efectivo del movimiento cooperativo radicado en el ámbito rural, para el caso del algodón. El estudio realizado lo demuestra. El cultivo algodonero depende del trabajo familiar, que poco atiende a la calidad del producto aunque su relación sea directa con la instalación de las fábricas textiles en la Argentina, dedicadas preferentemente a la confección de envases (bolsas) para productos del agro. En el caso del tabaco también este análisis muestra un proceso lento y bastante sinuoso pero que se enlaza a una industria manufacturera concentrada y de alto rendimiento, a la recaudación fiscal por parte del Estado y al abandono de productores y cosecheros, toda vez que el tabaco importado suple con creces al de origen criollo.

En tiempos del intervencionismo de Estado de los años 30, primero, y del gobierno peronista, después, el nacionalismo económico avanza, tratando —no siempre con éxitode distribuir la radicación de la riqueza y el trabajo en todo el territorio argentino. Lo hace por medio de instituciones reguladoras, de una legislación que orienta la producción y la comercialización de la misma y de la asignación de crédito barato. Es el Estado popular, nacionalista y benefactor liderado por Juan D. Perón el que opta por la redistribución del ingreso en beneficio de la pequeña y mediana industria nacional que produce para un mercado interno en expansión, y entonces - en un primer momento- el papel jugado por el cooperativismo es puesto en cuestión, mientras se redoblan las medidas capaces de alentar la industria liviana en sus diversas formas, pero esencialmente las ligadas al empleo de materias primas internas.

Las relaciones entre el gobierno y el movimiento cooperativo se tornan tensas en la primera etapa de la gestión peronista; pero no por mucho tiempo. Los desajustes ${ }^{82}$ ocurridos en 
la economía argentina a partir de 1949, el cambio de rumbo y con él "la vuelta al campo", hacen de las cooperativas agrarias un instrumento requerido por el Estado para reducir los costos de intermediación. El crédito oficial se pone al servicio de las actividades del agro y las cooperativas agrarias (no sólo algodoneras) son llamadas a jugar un papel trascendente en esta reorganización exigida por la nueva coyuntura por la que transita el país.

El Gran Chaco Argentino y su producción de algodón resultan una muestra acabada (independientemente de cuánto dure su éxito) de la decisión estatal y de los empresarios por encontrar una salida a la marginalidad económica, en este caso del Nordeste Argentino, donde el sistema cooperativo juega un papel trascendente. El Estado Nacional lo hace para contrarrestar el desempleo, fortalecer la pequeña y mediana industria nativa y mantener el control social, aunque el discurso apele a destacar la importancia de las medidas para que la región del Gran Chaco Argentino supere su postergación. Los empresarios nacionales, en cambio, apuestan a diversificar sus inversiones, disminuir el riesgo inversor y aumentar sus capitales. Los pequeños y medianos productores algodoneros consideran que este cultivo tiene futuro en un mercado interno fortalecido con el auspicio gubernamental, aunque sin ponderar el porcentual de reinversión de las ganancias que tendrá lugar en la zona.

En el caso del tabaco, la precariedad del productor y del cosechero, su desarraigo y las características propias del cultivo que se manufactura a gran distancia de la zona de producción de la materia prima y se lleva a cabo mediante una industria concentrada y sin una alta tecnología, la función del cooperativismo es casi inexistente. Los sectores bajos son los que corren todos los riesgos de la actividad tabacalera, mientras los grandes industriales no dejan de manufacturar un producto de alta calidad que por lo general importan.

El aumento de la superficie sembrada con algodón, que supone la incorporación de nuevas tierras de la planicie chaqueña, entre 1930 y 1960, resulta más regular que la producción de fibra. Hacia fines de la década de 1950 la competencia de las fibras sintéticas — registrada en los avisos de las publicaciones periódicas-, los cambios en la demanda, las restricciones en el consumo por la preferencia de las fibras artificiales, la competencia de las zonas irrigadas de Santiago del Estero productoras de algodón de fibras largas y los efectos de los ajustes introducidos en la economía nacional para operar "la vuelta al campo" desde 1949, pone nuevamente en el centro del interés gubernamental a las producciones rurales de la rica región pampeana y reducen las opciones del Gran Chaco Argentino para que con "el oro blanco" pueda remontar su condición de región marginal. La pervivencia del monocultivo de carácter minifundista, acentúa la postergación de estas áreas ecológicamente devastadas. En síntesis, y más allá de las diferencias propias de cada actividad económica, los productores (especialmente los pequeños y medianos) siguen viviendo, a las puertas de 1960, en medio de una precariedad que pone en duda al algodón y al tabaco en tanto opciones reales para la economía del Gran Chaco Argentino, tal como se pensara en los esperanzados años 20.

\section{Fuentes}

Anales de Legislación Argentina (1949)

Administración General De Impuestos Internos

Memoria correspondiente al año 1936

Archivo del Banco de La Nación Argentina (ABNA)

Sección Carpetas Especiales: Comisión Mixta para elaborar un plan de créditos y organización de pre-cooperativa, Carpeta especial 313 
Libro de Actas del Directorio, setiembre 1947, t. 32, f. 30; junio 1948, t. 66, f. 33; diciembre 1948, t. 92, f. 66; noviembre 1949, t. 134, fs. 197-198; agosto 1950, t. 169, f. 26; enero 1952, t. 224, f. 109; noviembre 1952, t. 255, f. 112

Archivo Histórico del Chaco (AHCh)

Territorio Villa Angela. Municipalidad, 1936-1946. Caja núm. 2. Villa Angela, diciembre 19 de 1946, sin foliar

Territorio El Pintado. Comisión de Fomento, 1919-1949. Folio 418, letra P, diciembre 19 de 1921

Territorio Avia Terai. Comisión de Fomento, 1926-1951. Caja núm. 1, marzo 3 de 1949, fs. 459 y afiche del Comité local del Partido Comunista

Época Territorial. Gobernación del Chaco. Notas enviadas (Huelgas Agrarias), años 1933, 1934, 1936 y 1938_ Caja 21.1, fs. 1-37, mayo 15 de 1934

Material sin catalogar. Asociación gremial de Productores Agrarios de las Breñas, 1947-1961. Legajo 2017, fs. 6-20

La Cooperación. Órgano de la Asociación de Cooperativas Argentinas (OACA)

Buenos Aires, 16 de agosto de 1946, núm. 929; 7 de mayo de 1948, núm. 1017; 14 de abril de 1950, núm. 1113; 6 de abril de 1951, núm. 1164; 18 de octubre de 1952, núm. 1243; 18 de junio de 1954, núm. 1329; 26 de marzo de 1954, núm. 1317; 3 de septiembre de 1954, núm. 1340; 15 de octubre de 1954, núm. 1346

\section{La Chacra}

Buenos Aires, Editorial Atlántida, agosto de 1946; febrero de 1948

La Gaceta Algodonera (GA)

Publicación defensora de plantadores e industriales de algodón, Buenos Aires, febrero 29 de 1924, año 1, núm. 1; noviembre 30 de 1924, año 1, núm. 10; mayo 31 de 1924, año 1, núm.4; febrero 28 de 1926, año 2, núm. 25; mayo 31 de 1926, año 2, núm. 28; agosto 31 de 1926, año 2, núm. 31; febrero 28 de 1927, año 2, núm.37; julio 31 de 1927, año 2, núm.42; setiembre 30 de 1928, año 5, núm.56; enero 31 de 1930, año 6, núm. 72; julio 31 de 1930, año 7, núm. 78; agosto 31 de 1930, año 7, núm. 79; noviembre 30 de 1930, año 7, núm. 82; enero 31 de 1931, año 7, núm. 84; marzo 31 de 1931, año 8, núm. 86; marzo 31 de 1940, núm. 194; octubre 31 de 1940, año 17, núm. 201; junio 30 de 1941, año 18, núm. 209; agosto 31 de 1941, año 18, núm. 211; setiembre 30 de 1941, año 18, núm. 212; diciembre 31 de 1941, año 18, núm. 215

Junta Nacional para Combatir la desocupación Memoria elevada al Ministerio del Interior (1936)

Ministerio de Agricultura de la Republica Argentina (MARA)

Junta Nacional del Algodón. Boletín Mensual: junio de 1940, núm. 62; agosto de 1940, núm. 64; diciembre de 1940, núm. 68; enero de 1941, núm.69; junio de 1941, núm. 74; enero-febrero de 1942, núm. 81-82; enero de 1943, núm. 93; julio-agosto de 1942, núm. 87-88; noviembre-diciembre de 1942, núm. 91-92; enero-febrero de 1945, núm. 117-118; mayo-junio de 1945, núm. 121122; setiembre-octubre de 1945, núm. 125-126; mayo-junio de 1946, núm. 133-134; mayo-junio de 1947, núm. 145-146

Junta Nacional del Algodón. Memoria mayo-diciembre (1935)

Ministerio de Finanzas de la Nación. Banco de Crédito Industrial Argentino (1952)

Reglamentaciones sobre créditos especiales, 1947-1951

Oro Blanco. Economía, vulgarización y tecnicismo. Revista mensual del algodón, año 1, núm. 3.1936

Revista de Economía Argentina (REA)

Buenos Aires, diciembre de 1929, año 12, tomo XXIII, núm. 138; julio de 1930, año 13, tomo XXV, núm. 145; octubre de 1937, año 19, tomo XXXVI, núm. 232. 
Poder Ejecutivo Nacional. Secretaría de Estado de Hacienda

Anuario estadístico de la República Argentina, 1957, Buenos Aires, Dirección Nacional de Estadística y Censos

Banco de la Nación Argentina

El crédito agrario en el banco de la nación argentina, Buenos Aires, Banco de la Nación Argentina (1945)

Departamento Nacional de Trabajo (DNT)

La desocupación en la argentina (1932)

Gobernación del Chaco de la Republica Argentina

Memoria presentada al superior gobierno de la nación. Año 1935. José c. Castells, gobernador, Resistencia

Secretaría de Industria y Comercio (SIC)

Dirección de tabaco: Boletín del tabaco, enero marzo de 1947, año XI; julio setiembre de 1947, año XI; enero marzo de 1948, año XII

Dirección de Tabaco: Cartilla para el cultivo del tabaco (1946)

\section{Bibliografía}

BRUNIARD, Enrique D. (1975-1978): “El Gran Chaco Argentino (ensayo de interpretación geográfica)", Geográfica. Revista del Instituto de Geografía 4, Resistencia (Chaco), Instituto de Geografía, Facultad de Humanidades de la Universidad Nacional del Nordeste.

CALVO, Jorge Raúl (s/f): El "oro blanco" en la Argentina. Estudio económico-social del algodón, Buenos Aires, Editorial Claridad.

CAVALLONE BREBBIA, Adolfo (1947): Cooperativismo. Sociedades cooperativas en la República Argentina, Buenos Aires, Editorial Semca.

DANERI, Manuel J. (1938): La política tabacalera. Tesis presentada para optar al título de Doctor en Ciencias Económicas, Buenos Aires, Facultad de Ciencias Económicas de la universidad de Buenos Aires.

GIRBAL-BLACHA, Noemí M. (1988): Estado, chacareros y terratenientes (1916-1930). Política agraria y relaciones de poder, Buenos Aires, Centro Editor de América Latina, Biblioteca Política Argentina 211.

-(2003): Mitos, paradojas y realidades en la Argentina peronista (1946-1955). Una interpretación histórica de sus decisiones politico-económicas, Buenos Aires, Editorial de la Universidad Nacional de Quilmes.

-(2005): “Algodón, envases textiles y tejeduría doméstica. Propuestas industrializadoras del Estado interventor en la Argentina de los años 1940", Revista de Historia Industrial. Economía y Empresas 27, año XIV, I, Barcelona Universitat de Barcelona, pp. 91-120.

-(2007): "Estado y regulación económica en el Norte argentino. El tabaco en la década de 1930", Historia Agraria. Revista de agricultura e historia rural 41, abril, SEHA- Murcia (España), pp. 83-105.

-(2008): "Justicia fiscal" o "inconvenientes del empirismo": una cuestión de privilegio. Industriales y productores tabacaleros en la Argentina, 1920-1960", Estudos Ibero Americano, Vol. 34, n. ${ }^{\circ}$ 2, julho-dezembro, PCRS-CNPq, Porto Alegre- Brasil, pp. 49-75.

GRATTAROLA, Lázaro B. (1954): Cooperativismo en la República Argentina, Santa Fe, sin editorial. GUY, Donna J. (2000): “El Rey Algodón”, Los Estados Unidos, la Argentina y el desarrollo de la industria algodonera argentina", Mundo Agrario. Revista de Estudios Rurales, 1, segundo semestre, Centro de Estudios Histórico Rurales de la Universidad Nacional de La Plata, 
formato electrónico.

KAPLAN de DRIMER, Alicia y KAPLAN, Bernardo (1975): Las cooperativas. FundamentosHistoria-Doctrina, Buenos Aires, Intercoop/F.A.C.C.

MATEO, Graciela (2006): “La educación cooperativa: entre la doctrina y la experiencia, entre las políticas públicas y las prácticas institucionales, 1940-1955", OLIVERA, Gabriela (comp.), Cooperativismo Agrario: Instituciones, Politicas Públicas y Procesos Históricos, Córdoba, Ferreira Editor, pp. 59-81.

-(2008): "Economía social y agrocooperativas. La vigencia de un modelo", BALSA, Javier, MATEO, Graciela y OSPITAL, María Silvia (comp.), Pasado y Presente en el Agro Argentino, Buenos Aires, Editorial Lumière, pp. 235-256.

MATEO, Graciela y GUTIERREZ, Talía V. (2007): “Historia agraria y recuperación de la memoria local, Gualeguaychú (Entre Ríos)", Introducción del Dossier, en Mundo Agrario, Revista de estudios rurales, CEHR, Facultad de Humanidades y Ciencias de la Educación, UNLP, N. ${ }^{\circ} 16$, primer semestre, pp. 1-9.

MUELLO, Carlos Alberto (s / f): Geografía económica del Chaco y Formosa, Buenos Aires, Gráfica Oceana.

SCOBIE, James R. (1988): Secondary Cities of Argentina. The Social History of Corrientes, Salta, and Mendoza, 1850-1910, Completed and Edited by Samuel L. Baily, Stanford, Stanford University Press.

THIERY, René R (1955): “Legislación argentina comparada”, en MINISTERIO DE FINANZAS DE LA NACION. BANCO DE LA NACION ARGENTINA, Curso sobre cooperativismo, Buenos Aires, Talleres Gráficos "Index", pp. 10-22.

YURI IZQUIERDO, Mario (1972): Quince años en el cooperativismo agrario argentino (1953-1968), Buenos Aires, Intercoop Editora Cooperativa Ltda. 